\title{
Correction: Binaural Fusion and Listening Effort in Children Who Use Bilateral Cochlear Implants: A Psychoacoustic and Pupillometric Study
}

Morrison M. Steel, Blake C. Papsin, Karen A. Gordon

In Fig 4,there is an error with the legends for Normal Hearing and Cochlear Implant. Please view the correct Fig 4 here.

\section{Gopen ACcess}

Citation: Steel MM, Papsin BC, Gordon KA (2015) Correction: Binaural Fusion and Listening Effort in Children Who Use Bilateral Cochlear Implants: A Psychoacoustic and Pupillometric Study. PLoS ONE 10(10): e0141945. doi:10.1371/journal.pone. 0141945

Published: October 30, 2015

Copyright: @ 2015 Steel et al. This is an open access article distributed under the terms of the Creative Commons Attribution License, which permits unrestricted use, distribution, and reproduction in any medium, provided the original author and source are credited. 
a) Measured responses

$\mathrm{L} / \mathrm{Cl}-2$ held at $\mathrm{T}+10$

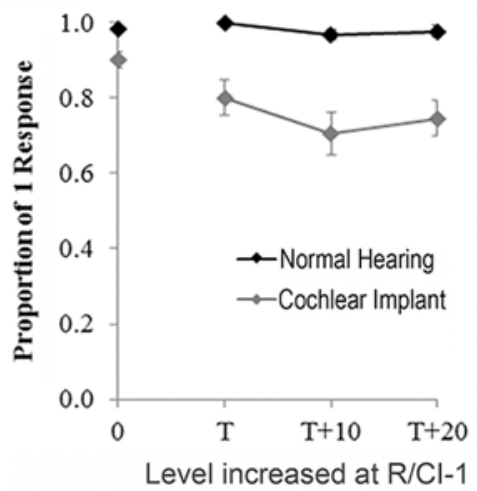

$\mathrm{R} / \mathrm{Cl}-1$ held at $\mathrm{T}+10$

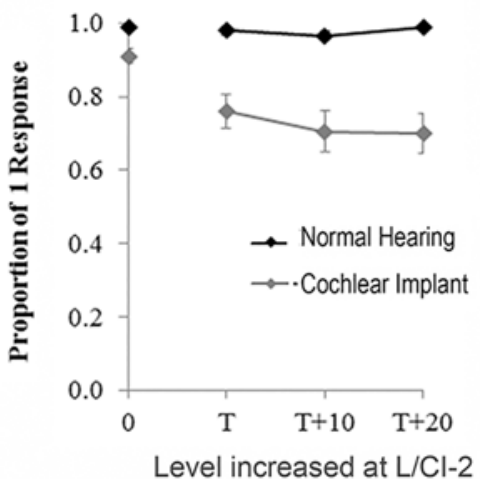

b) Predicted responses

$\mathrm{L} / \mathrm{Cl}-2$ held at $\mathrm{T}+10$

$\mathrm{R} / \mathrm{Cl}-1$ held at $\mathrm{T}+10$

Children with Normal Hearing
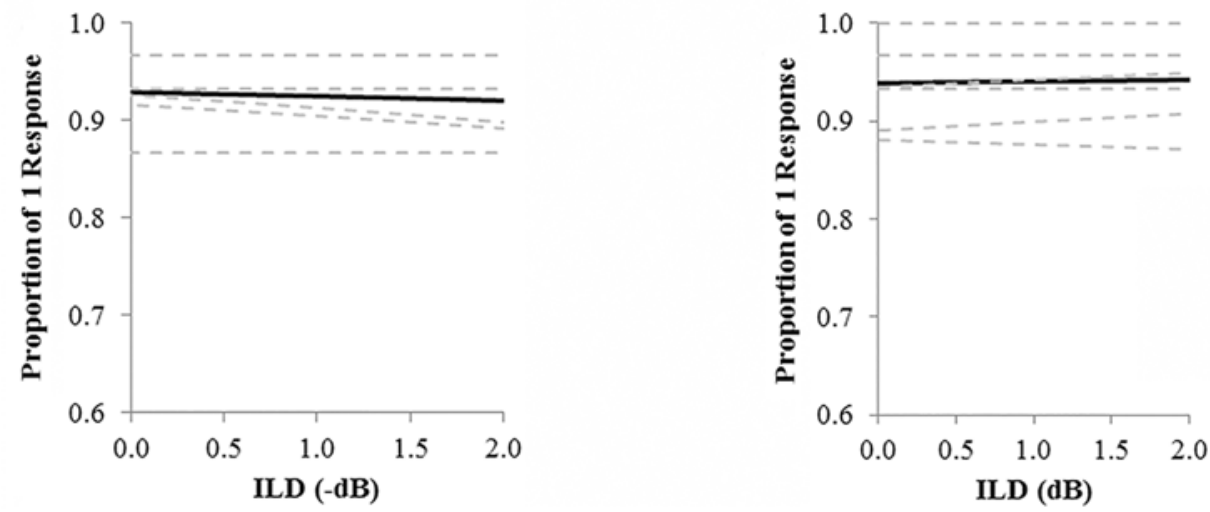

Children with Bilateral Cochlear Implants
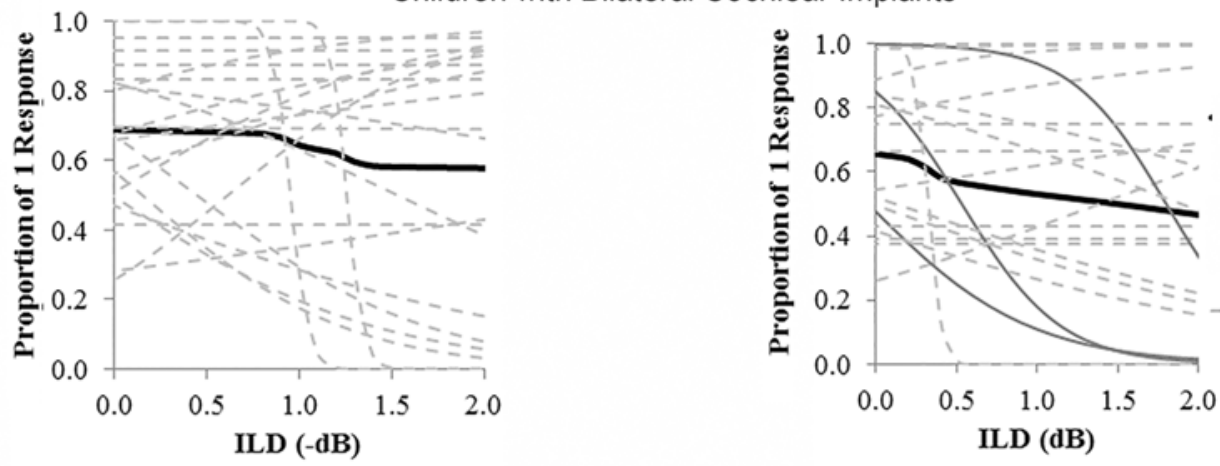

- Mean Change

- - -Non- Significant Change

- Significant Change

Fig 4. Fusion with interaural level differences. a) Group performance for conditions containing ILDs (ITD $=0 \mathrm{~ms}$ ). Biphasic pulses were delivered from electrode 20 in the $\mathrm{Cl}$ group $(n=25)$. Cl listeners consistently perceived one image when there were level differences, albeit less frequently than $\mathrm{NH}$ peers $(n=24 ; p<0.0001)$. b) Binaural fusion was predicted as a function of ILD for individual normal hearing 
children and $\mathrm{Cl}$ users with logistic regression. None of the slopes were significant in the normal hearing children as shown by the dashed lines $(p>0.05)$. For $\mathrm{Cl}$ users, the majority of curves tend to decrease as a function of increasing ILD. Significant slopes $(n=3)$ are represented by dark grey solid lines.

doi:10.1371/journal.pone.0141945.g001

\section{Reference}

1. Steel MM, Papsin BC, Gordon KA (2015) Binaural Fusion and Listening Effort in Children Who Use Bilateral Cochlear Implants: A Psychoacoustic and Pupillometric Study. PLoS ONE 10(2): e0117611. doi:10.1371/journal.pone.0117611 PMID: 25668423 